\title{
Polymorphisms in the $X R C C 1$ gene are associated with treatment response to platinum chemotherapy in advanced non-small cell lung cancer patients based on meta-analysis
}

\author{
L. Li, C. Wan and F.Q. Wen \\ Division of Pulmonary Diseases, State Key Laboratory of Biotherapy of China, \\ and Department of Respiratory Medicine, \\ West China Hospital of Sichuan University, Chengdu, China \\ Corresponding author: F.Q. Wen \\ E-mail: wenfuqiang.scu@gmail.com
}

Genet. Mol. Res. 13 (2): 3772-3786 (2014)

Received December 6, 2012

Accepted June 7, 2013

Published May 16, 2014

DOI http://dx.doi.org/10.4238/2014.May.16.1

ABSTRACT. X-ray repair cross complementing group 1(XRCC1)
polymorphisms have been implicated in interindividual variability of
efficacy of platinum chemotherapy for treating non-small cell lung cancer
(NSCLC); however, results of different studies have been inconsistent.
We conducted a meta-analysis to investigate the association between
polymorphisms in the XRCC1 gene and response rate of platinum
chemotherapy in advanced NSCLC patients. Searches were performed
on MEDLINE, PubMed, EMBASE, Chinese Biological Medicine
Database, China National Knowledge Infrastructure, and Wangfang
Data, covering all relevant studies published up to August 1, 2012.
Statistical analyses were performed using the Revman 5.0 and STATA
10.0 software. Two polymorphisms, Arg399Gln (G>A) and Arg194Trp
(C $>$ T), were investigated in 19 studies, involving 2152 advanced NSCLC
patients. For XRCC1 Arg399Gln, patients carrying two G alleles had a
significantly increased response rate of platinum chemotherapy, when 
compared with those carrying the A allele [odds ratio $(\mathrm{OR})=2.05,95 \%$ confidence interval $\mathrm{CI}=1.62-2.60$ for GG $v s \mathrm{GA}+\mathrm{AA}]$. Similarly, the AA carriers had a $54 \%$ decreased response rate compared with the $\mathrm{G}$ allele carriers $(\mathrm{OR}=0.46,95 \% \mathrm{CI}=0.30-0.70$ for $\mathrm{AA} v s \mathrm{GA}+\mathrm{GG})$. For XRCC1 Arg 194Trp, patients carrying two C alleles had a $62 \%$ decreased response rate compared with those carrying either one or two variant $\mathrm{T}$ alleles $(\mathrm{OR}=0.38,95 \% \mathrm{CI}=0.30-0.48$ for $\mathrm{CC} v \mathrm{CT}+\mathrm{TT})$. However, although TT carriers had a better response rate compared with the $\mathrm{C}$ allele carriers, the difference was not significant $(\mathrm{OR}=1.27,95 \% \mathrm{CI}=$ 0.92-1.77 for TT vs CC+CT). Based on this meta-analysis, we conclude that $X R C C 1$ polymorphisms are associated with treatment response to platinum chemotherapy in advanced NSCLC patients.

Key words: Lung cancer; $X R C C 1$; Gene polymorphism; Platinum; Chemotherapy; Meta-analysis

\section{INTRODUCTION}

Non-small cell lung cancer (NSCLC) is the most common type of lung cancer (Jemal et al., 2011). Most NSCLC patients are diagnosed with advanced or metastatic disease at first presentation, so platinum chemotherapy is still the mainstay of initial treatment for those patients. However, treatment effects remain moderate and vary remarkably between individuals, with a response rate from 26 to $60 \%$ (Bahl and Falk, 2001). Therefore, it is important to identify which tumor cells that are sensitive to platinum compounds.

Platinum induces apoptosis of tumor cells through the formation of cytotoxic platinum-DNA adducts that result in the distortion of DNA, destabilization of the double helix, and block of DNA replication (Shellard et al., 1993), but DNA repair systems recognize and repair various forms of DNA-damage to maintain DNA integrity. There are four major DNA repair pathways known: base excision repair (BER), nucleotide excision repair (NER), mismatch repair (MMR), and double strand break repair (DSBR) (Wood et al., 2001). Although the NER pathway is the major repair mechanism for platinum-DNA adducts, other studies support the proposal of overlapping repair pathways involved in alternative repair of platinum adducts, such as the BER pathway (Wood et al., 2001; Weaver et al., 2005). X-ray repair cross complementing group 1 (XRCC1) gene, located on chromosome 19q13.2, has long been recognized as a key component of the BER pathway, acting as a "scaffold" for the coordination of other BER proteins at the sites of base damage during repair (Hoeijmakers, 2001; Whitehouse et al., 2001). XRCC1 has also been proposed to be involved in the repair of other types of DNA damage caused by platinum, including DNA double-strand breaks (Audebert et al., 2004). Additionally, the $X R C C 1$ transcript abundance level has been demonstrated to correlate with cisplatin chemoresistance in NSCLC cell lines (Weaver et al., 2005). Therefore, XRCC1 may have some relationship with the efficacy of platinum chemotherapy.

Theoretically, genetic polymorphisms in the $X R C C 1$ gene should modulate DNA repair capacity and hence influence the anticancer effect of platinum drugs and reveal platinum sensitivity in NSCLC patients. In vitro studies have demonstrated that Arg399Gln polymorphisms in the $X R C C 1$ gene is associated with the persistence of DNA adducts (Lunn et al., 
1999; Duell et al., 2000), increased sister chromatid exchanges (Duell et al., 2000; Abdel-Rahman and El-Zein, 2000), and prolonged cell cycle delay (Hu et al., 2001). Many clinical studies have investigated the association between $X R C C 1$ polymorphisms and treatment response to platinum chemotherapy in advanced NSCLC patients, but the results are inconsistent. Because a single study may lack the power to provide comprehensive and reliable conclusions, a systematic review and meta-analysis of all eligible studies was performed to investigate the association between XRCC1 polymorphisms and response rate of platinum chemotherapy in advanced NSCLC patients.

\section{MATERIAL AND METHODS}

\section{Literature search and study selection}

MEDLINE, PubMed, EMBASE, Chinese Biological Medicine Database (CBM), China National Knowledge Infrastructure (CNKI), and Wangfang Data were searched to identify studies that had investigated the association between $X R C C 1$ polymorphisms and response rate of platinum chemotherapy in advanced NSCLC patients. The last updated search was performed on August 1, 2012. The broad search terms were: "XRCC1," "X-ray cross-complementing group 1", "lung cancer", "polymorphism", "platinum", and "chemotherapy". No language restriction was applied. Search strategies are shown in the Supplementary material.

Duplicate and obviously unrelated articles were removed by a single reviewer (L.L.). Relevant studies on XRCC1 polymorphisms and platinum chemotherapy in NSCLC were identified. Titles and abstracts of these remaining articles were screened independently by two reviewers (L.L. and W.C.) to determine whether the full-text article should be retrieved for further assessment. During in-depth full-text review for eligibility, the inclusion criteria were as follows: 1) patients had pathologically confirmed advanced, recurrent, or metastatic NSCLC, 2) platinum chemotherapy served as therapeutic schedule, 3) $X R C C 1$ polymorphisms were genotyped, 4) primary outcome was response to chemotherapy, and results were presented by stratification of XRCC1 polymorphisms. The following exclusion criteria were also applied: 1) studies involved several types of lung cancer but not NSCLC alone, 2) neoadjuvant chemotherapy was involved, 3 ) other treatment was involved, such as surgery and radiotherapy, 4) invalid data or critical missing information was not obtained by our repeated contacts with the corresponding authors, 5) basic studies including animals and lung cancer cell lines were involved. Different opinions were resolved by discussion to reach consensus between the two reviewers.

\section{Quality assessment}

Two reviewers (L.L. and C.W.) independently assessed the quality of all included studies using the Newcastle-Ottawa Quality Assessment Scale for cohort studies (Wells et al., 2003). The eight-item scale is recommended by the Cochrane Non-Randomized Studies Methods Working Group (The Cochrane Collaborative Review Group on HIV Infection and AIDS, 2009), and composed of three categories: selection, comparability, and outcome. Stars are awarded to high-quality elements and are used to compare study quality in a quantitative manner. There are four items in the Selection category and three items in the Outcome cat- 
egory; a study can be awarded one star for each item in these categories. There two items in the Comparability category and a maximum of two stars can be given for comparability. Studies that fulfill 5 or more of the 8 criteria are higher-quality studies (Wells et al., 2003). Disagreement was resolved by consensus.

\section{Data extraction}

Two reviewers (L.L. and C.W.) extracted data from the included studies independently. A pre-specified extraction form was used and included the following information: first author's name, year of publication, country, sample size, clinical stage of lung cancer, XRCC1 polymorphisms, genotyping methods, and type of platinum drugs. Different opinions were resolved by consensus.

\section{Statistical methods}

In a meta-analysis, a small number of studies weaken the conclusions; therefore, only those polymorphisms that had been investigated in at least five studies were included in the present study. The genetic models evaluated for these polymorphisms were dominant models as well as recessive models if possible.

The endpoints considered in the pooled analyses were response rate. The WHO criteria (Miller et al., 1981) or the Response Evaluation Criteria in Solid Tumors (RECIST) (Therasse et al., 2000) were used to define response, with "complete response" or "partial response" classified as "response", and "stable" or "progressive" disease classified as "non-response". Odds ratio (OR) and the corresponding $95 \%$ confidential interval (CI) were calculated to assess the strength of the association between XRCC1 polymorphisms and response rate of platinum chemotherapy. The significance of the pooled OR was determined by the $Z$-test, and $\mathrm{P}<$ 0.05 was considered statistically significant.

Heterogeneity was assessed by the Q statistic test. P $>0.10$ for the $\mathrm{Q}$ test indicates a lack of heterogeneity between studies. The fixed-effect model was used to estimate the pooled OR if absence of heterogeneity was suggested by this test; otherwise, a random-effect model was used. Asymmetry of funnel plots was visually inspected to assess potential publication bias. The Egger test and Begg test were performed to provide statistical evidence of funnel plot asymmetry. To evaluate the ethnicity-specific and platinum drug-specific effects, subgroup analyses were performed for both polymorphisms if they were investigated in a sufficient number of studies. software.

All statistical analyses were performed using the Revman5.0 software and STATA10.0

\section{RESULTS}

\section{Studies included in the meta-analysis}

Sixty-three relevant papers were identified, and after screening titles and abstracts, 39 publications were selected for full-text review. An additional 20 articles were excluded. Four reported survival and prognosis, six did not report treatment or use platinum chemo- 
therapy as treatment, two were neoadjuvant chemotherapy, two reported $X R C C 1$ polymorphisms and toxicity of cisplatin-based chemotherapy, one reported XRCC1 polymorphisms and risk of lung cancer, one reported on T-77C polymorphism, one was a SCLC study, two presented data for both NSCLC and SCLC but not NSCLC alone, and one did not report usable data with authors being unreachable. Therefore, the final data pool consisted of 19 studies (Wang et al., 2004; Yuan et al., 2006; Gao et al., 2006; Jin et al., 2006; Song et al., 2007a,b; Fan et al., 2008; Hong et al., 2009; Sun et al., 2009; Qiu et al., 2009; Kalikaki et al., 2009; Yao et al., 2009; Qian et al, 2010; Ding et al., 2010; Zhou et al., 2011a,b; Cheng et al., 2011; Xu et al., 2011; Li et al., 2012), including 2152 stage III/IV NSCLC patients. The groups of both Zhou and Song had investigated XRCC1 polymorphisms and treatment response to platinum chemotherapy in two independent populations with separate analyses of the data, so these data produced four independent studies (Duell et al., 2000; AbdelRahman and El-Zein, 2000) (Song et al., 2007a,b; Zhou et al., 2011a,b). Information about this search process is illustrated in a flow chart in Figure 1. The characteristics of each study are shown in Table 1.

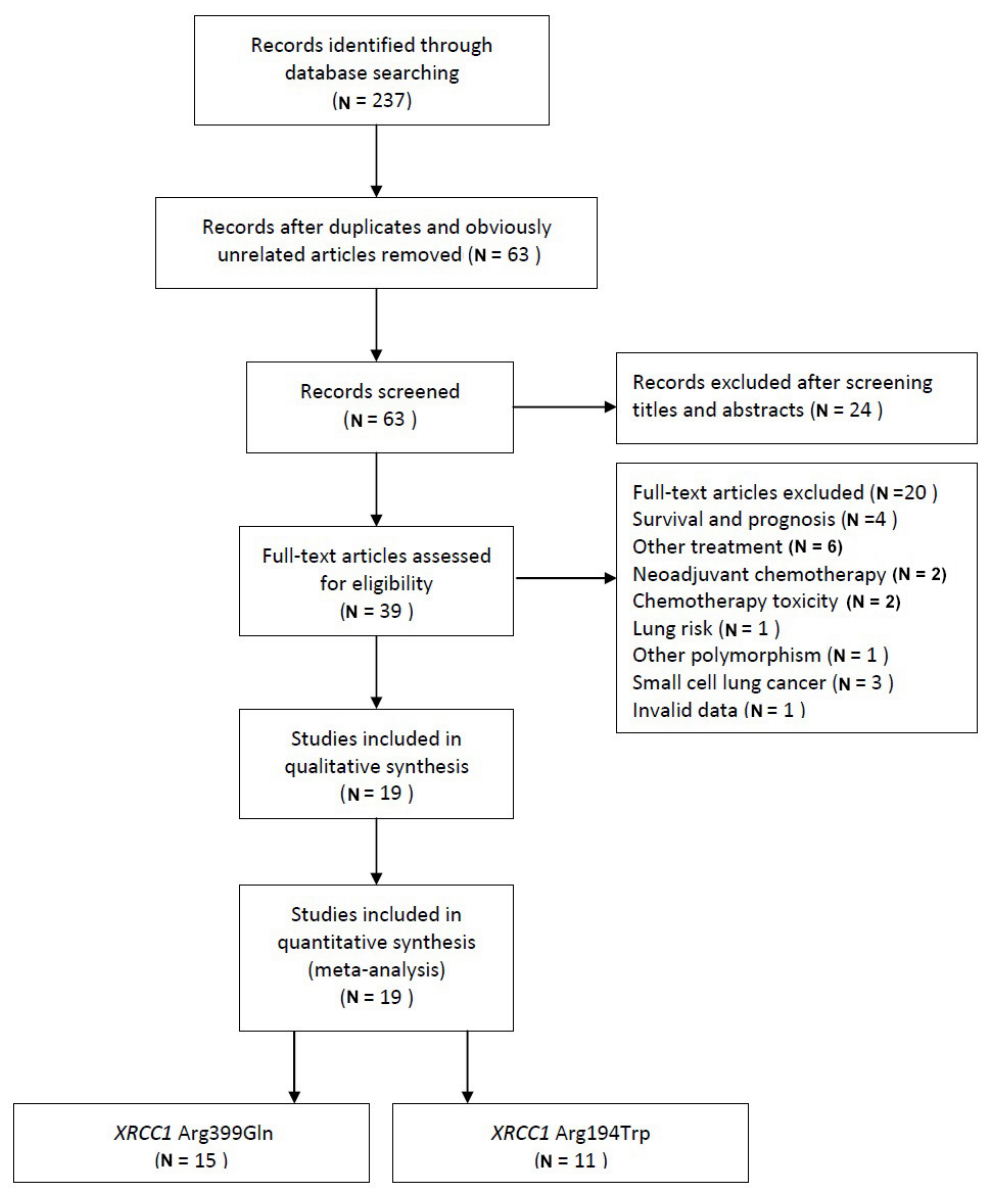

Figure 1. Flow chart of study selection. 
Table 1. Characteristics of studies included in the meta-analysis.

\begin{tabular}{|c|c|c|c|c|c|c|c|}
\hline $\begin{array}{l}\text { First } \\
\text { author }\end{array}$ & $\begin{array}{c}\text { Year of } \\
\text { publication }\end{array}$ & Country & $\begin{array}{l}\text { Sample } \\
\text { size }\end{array}$ & $\begin{array}{l}\text { Clinical } \\
\text { stage }\end{array}$ & $\begin{array}{l}X R C C 1 \\
\text { polymorphisms }\end{array}$ & $\begin{array}{l}\text { Genotyping } \\
\text { methods }\end{array}$ & $\begin{array}{l}\text { Type of } \\
\text { platinum }\end{array}$ \\
\hline Zhou F & $2011 b$ & China & 111 & IV & XRCC1Arg399Gln & PCR & DDP, CBP \\
\hline Zhou F & $2011 \mathrm{a}$ & China & 94 & IIIB-IV & XRCC1Arg399Gln & PCR & DDP \\
\hline Song DG & $2007 \mathrm{a}$ & China & 166 & IIIB-IV & XRCC1Arg194Trp & PCR-RFLP & DDP \\
\hline \multirow[t]{2}{*}{ Song DG } & $2007 \mathrm{~b}$ & China & 97 & IIIB-IV & XRCC1Arg 194Trp & & \\
\hline & & & & & XRCC1Arg399Gln & PCR-RFLP & DDP, CBP \\
\hline Li DR & 2011 & China & 89 & III-IV & XRCC1Arg399Gln & PCR & DDP \\
\hline \multirow[t]{2}{*}{ Hong CY } & 2009 & China & 164 & III-IV & XRCC1Arg194Trp & & \\
\hline & & & & & XRCC1Arg399Gln & PCR-RFLP & DDP \\
\hline \multirow[t]{2}{*}{ Wang ZH } & 2004 & China & 105 & IIIB-IV & XRCC1Arg194Trp & & \\
\hline & & & & & XRCC1Arg399Gln & PCR-RFLP & DDP, CBP \\
\hline \multirow[t]{2}{*}{ Sun XC } & 2009 & China & 87 & IV & XRCC1Arg194Trp & & \\
\hline & & & & & XRCC1Arg399Gln & PCR & DDP, CBP \\
\hline Jin YW & 2006 & China & 162 & IIIB-IV & XRCC1Arg 194Trp & PCR-RFLP & DDP, CBP \\
\hline Qian XP & 2010 & China & 107 & IIIB-IV & XRCC1Arg399Gln & PCR-RFLP & Platinum \\
\hline \multirow[t]{2}{*}{ Gao CM } & 2006 & China & 57 & $\mathrm{II}-\mathrm{IV}(\mathrm{II}=1)$ & XRCC1Arg194Trp & & \\
\hline & & & & & XRCC1Arg399Gln & PCR-RFLP & DDP \\
\hline \multirow[t]{2}{*}{ Ding CL } & 2010 & China & 54 & IIIB-IV & XRCC1Arg 194Trp & & \\
\hline & & & & & XRCC1Arg399Gln & PCR & DDP, CBP \\
\hline Yuan P & 2006 & China & 200 & IIIB-IV & XRCC1Arg194Trp & PCR-RFLP & DDP, CBP \\
\hline Qiu LX & 2009 & China & 107 & III-IV & XRCC1Arg 194Trp & PCR-RFLP & DDP, CBP \\
\hline Cheng HY & 2011 & China & 120 & III-IV & XRCC1Arg399Gln & PCR & DDP, CBP \\
\hline Kalikaki A & 2009 & Greece & 119 & III- IV & XRCC1Arg399Gln & PCR-RFLP & DDP \\
\hline Yao CY & 2009 & China & 102 & IIIB-IV & XRCC1Arg399Gln & PCR-RFLP & DDP, CBP \\
\hline Fan $\mathrm{H}$ & 2008 & China & 81 & IIIB-IV & XRCC1Arg399Gln & PCR-RFLP & Platinum \\
\hline \multirow[t]{2}{*}{$\mathrm{Xu} \mathrm{CA}$} & 2011 & China (Asian) & 130 & IIIB-IV & XRCC1Arg194Trp & & \\
\hline & & & & & XRCC1Arg399Gln & PCR-RFLP & DDP, CBP \\
\hline
\end{tabular}

$\overline{\mathrm{PCR}}=$ polymerase chain reaction; $\mathrm{PCR}-\mathrm{RFLP}=$ polymerase chain reaction-restriction fragment length polymorphism; $X R C C 1=\mathrm{x}$-ray repair cross complementation group 1 ; DDP $=$ cisplatin; $\mathrm{CBP}=$ carboplatin.

Only two polymorphisms, Arg399Gln (exon 10, base G>A) and Arg194Trp (exon 6 , base $\mathrm{C}>\mathrm{T}$ ) were finally included in the meta-analyses, while other polymorphisms such as $\mathrm{Arg} 280 \mathrm{His}$ (exon 9, G>A) and $-77 \mathrm{~T} / \mathrm{C}$ were excluded because of insufficient numbers of studies on each polymorphism. There were 15 studies on $\operatorname{Arg} 399 \mathrm{Gln}(\mathrm{G}>\mathrm{A})$ and 11 studies on $\operatorname{Arg} 194 \operatorname{Trp}(\mathrm{C}>\mathrm{T})$. The genetic models evaluated for these two polymorphisms were dominant models (GG vs AA $+\mathrm{GA}$ for Arg399Gln and CC vs TT $+\mathrm{CT}$ for Arg194Trp) as well as recessive models (AA vs GA+GG for Arg399Gln and TT vs CT +CC for Arg194Trp).

\section{Quality assessment}

We used the Newcastle-Ottawa Quality Assessment Scale to perform the quality assessment on all 19 studies. The studies included in this meta-analysis scored highly (Table 2). However, no study had compared baseline characteristics to assess comparability, because patients were grouped according to their XRCC1 polymorphisms.

\section{Quantitative data synthesis}

\section{XRCC1 Arg399GIn (G>A) polymorphism}

Fifteen studies reported the association between XRCC1 Arg399Gln polymorphism and response rate of platinum chemotherapy in advanced NSCLC patients (Table 3). However, 
4 studies presented data in the dominant model (GG vs AA+GA) alone (Table 3A), 2 studies only in the recessive model (AA vs $\mathrm{GA}+\mathrm{GG}$ ) (Table 3B), and the remaining 9 studies by genotypes of AA, GA, and GG, separately (Table 3C). Thus, we first estimated the association of 13 studies in the dominant model, and then 11studies in the recessive model.

\begin{tabular}{lcccc}
\multicolumn{2}{c}{ Table 2. Quality of studies included in the meta-analysis. } & & \\
\hline Studies & Selection (stars) & Comparability (stars) & Outcome (stars) & Total (stars) \\
\hline Zhou F (2011a) & 4 & 0 & 3 & 7 \\
Zhou F (2011b) & 4 & 0 & 3 & 7 \\
Song DG (2007a) & 4 & 0 & 3 & 7 \\
Song DG (2007b) & 4 & 0 & 3 & 7 \\
Li DR (2012) & 4 & 0 & 3 & 7 \\
Hong CY (2009) & 4 & 0 & 3 & 7 \\
Wang ZH (2004) & 4 & 0 & 3 & 7 \\
Sun XC (2009) & 3 & 0 & 3 & 7 \\
Jin YW (2006) & 4 & 0 & 3 & 7 \\
Qian XP (2010) & 4 & 0 & 3 & 7 \\
Gao CM (2006) & 4 & 0 & 3 & 7 \\
Ding CL (2010) & 4 & 0 & 3 & 7 \\
Yuan P (2006) & 4 & 0 & 3 & 7 \\
Qiu LX (2009) & 4 & 0 & 3 & 7 \\
Cheng HY (2011) & 4 & 0 & 3 & 7 \\
Kalikaki A (2009) & 3 & 0 & 3 & 7 \\
Yao CY (2009) & 4 & 0 & 3 & 7 \\
Fan H (2008) & 4 & 0 & 3 & 7 \\
Xu CA (2011) & 4 & 0 & & 7 \\
\hline
\end{tabular}

Table 3. Association between XRCC1 Arg399Gln polymorphism(G>A) and response rate of platinum chemotherapy.

A.

\begin{tabular}{|c|c|c|c|c|c|c|}
\hline \multirow[t]{2}{*}{ Studies } & \multicolumn{3}{|c|}{$\mathrm{G} / \mathrm{G}$} & \multicolumn{3}{|c|}{$\mathrm{G} / \mathrm{A}+\mathrm{A} / \mathrm{A}$} \\
\hline & Response & Non-response & Total & Response & Non-response & Total \\
\hline Zhou F (2011) & 29 & 42 & 71 & 6 & 34 & 40 \\
\hline Kalikaki A (2009) & 11 & 21 & 33 & 26 & 60 & 86 \\
\hline Li DR (2012) & 20 & 24 & 44 & 6 & 39 & 45 \\
\hline Zhou F (2011a) & 19 & 33 & 52 & 11 & 31 & 42 \\
\hline
\end{tabular}

B.

\begin{tabular}{lccccccc}
\hline Studies & \multicolumn{3}{c}{} & \multicolumn{2}{c}{$\mathrm{A} / \mathrm{A}$} & & \multicolumn{3}{c}{$\mathrm{G} / \mathrm{A}+\mathrm{G} / \mathrm{G}$} \\
\cline { 2 - 3 } & Response & Non-response & Total & & Response & Non-response & Total \\
\hline Yao CY (2009) & 9 & 48 & 57 & & 13 & 32 & 45 \\
Fan H (2008) & 13 & 32 & 45 & & 16 & 20 & 36 \\
\hline
\end{tabular}

\begin{tabular}{llllll} 
Fan $\mathrm{H}(2008)$ & 13 & 32 & 16 & 20 & 36 \\
\hline C. & &
\end{tabular}

\begin{tabular}{|c|c|c|c|c|c|c|c|c|c|}
\hline \multirow[t]{2}{*}{ Studies } & \multicolumn{3}{|c|}{$\mathrm{A} / \mathrm{A}$} & \multicolumn{3}{|c|}{$\mathrm{G} / \mathrm{A}$} & \multicolumn{3}{|c|}{$\mathrm{G} / \mathrm{G}$} \\
\hline & Response & Non-response & Total & Response & Non-response & Total & Response & Non-response & Total \\
\hline Sun XC (2009) & 1 & 3 & 4 & 8 & 22 & 30 & 14 & 39 & 53 \\
\hline Wang ZH (2004) & 2 & 8 & 10 & 9 & 33 & 42 & 22 & 31 & 53 \\
\hline Hong CY (2009) & 3 & 10 & 13 & 28 & 53 & 81 & 26 & 44 & 70 \\
\hline Song DG (2007b) & 1 & 4 & 5 & 11 & 29 & 40 & 18 & 34 & 52 \\
\hline Gao CM (2006) & 0 & 3 & 3 & 8 & 15 & 23 & 11 & 20 & 31 \\
\hline Qian XP (2010) & 2 & 6 & 8 & 14 & 26 & 40 & 32 & 27 & 59 \\
\hline Ding CL (2010) & 3 & 10 & 13 & 4 & 6 & 10 & 18 & 13 & 31 \\
\hline Cheng HY (2011) & 5 & 10 & 19 & 9 & 44 & 53 & 21 & 27 & 48 \\
\hline Xu CA (2011) & 0 & 10 & 10 & 14 & 40 & 54 & 30 & 36 & 66 \\
\hline
\end{tabular}

A. Four studies reporting response rate for the dominant model alone; B. Two studies reporting response rate only for the recessive model; C. Nine studies reporting response rate by genotypes of AA, GA, and GG separately. 


\section{$G / G$ vs $G / A$ A/A for the dominant model}

Thirteen studies on XRCC1 Arg399Gln polymorphism in the dominant model (GG vs $\mathrm{GA}+\mathrm{AA}$ ) were included in the meta-analysis.

As shown in Figure 2, we analyzed the heterogeneity of the dominant model for all 13 studies, and the value of $\chi^{2}$ was 16.16 with 12 degrees of freedom and $\mathrm{P}=0.18$ in a fixed-effect model. Additionally, $I^{2}$, another index of heterogeneity, was $26 \%$, suggesting mild heterogeneity. Thus, we chose the fixed-effect model to synthesize the data. The overall OR for GG genotypes versus GA+AA genotypes was $2.05(95 \% \mathrm{CI}=1.62-2.60)$, and the $Z$-test for overall effect was $5.92(\mathrm{P}<0.00001)$. These results suggested that patients carrying two $G$ alleles $(\mathrm{GG})$ had a significantly higher response rate of platinum chemotherapy when compared with those carrying the $\mathrm{A}$ allele $(\mathrm{GA}+\mathrm{AA})$.

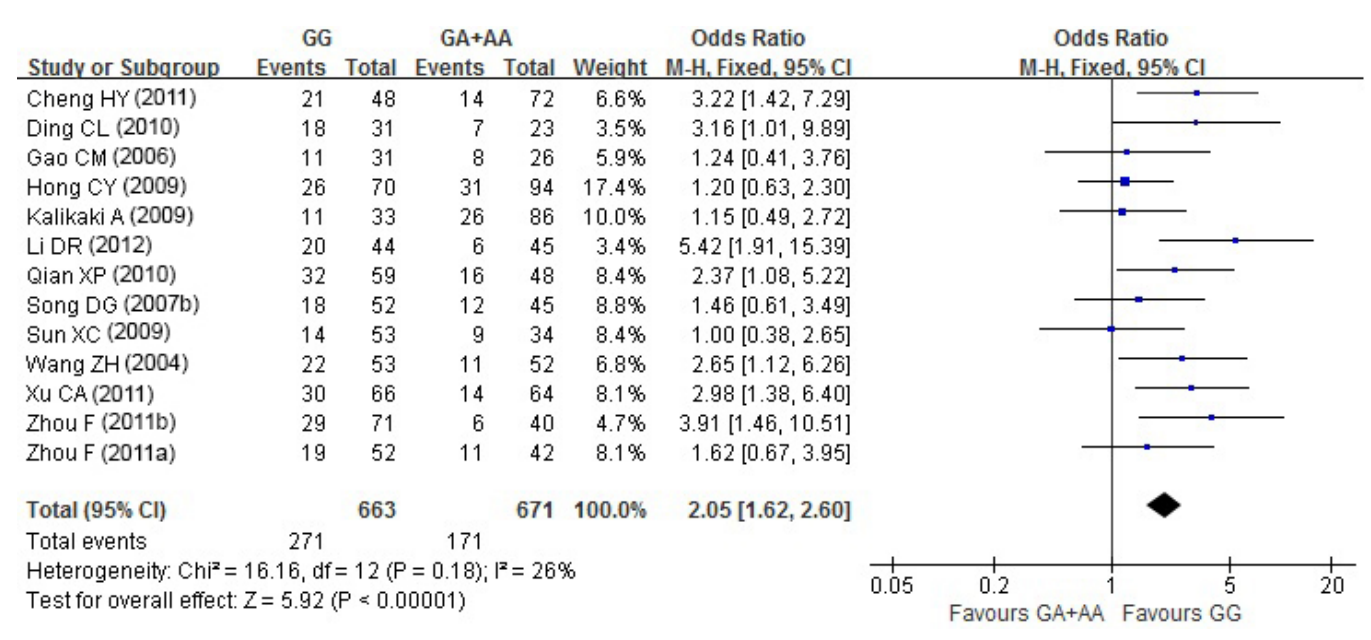

Figure 2. Forest plot of studies on the association between XRCC1 Arg399Gln polymorphism and response rate of platinum chemotherapy in advanced NSCLC patients, using the dominant model (GG vs GA+AA).

\section{$A / A$ vs $G / A G / G$ for the recessive model}

Eleven studies on XRCC1 Arg399Gln polymorphism in the recessive model (AA vs $\mathrm{GA}+\mathrm{GG})$ were included in the meta-analysis.

As shown in Figure 3, we analyzed the heterogeneity of the recessive model for all 11 studies, and the value of $\chi^{2}$ was 3.86 with 10 degrees of freedom and $\mathrm{P}=0.95$ in a fixed-effect model. Additionally, $I^{2}$ was $0 \%$, suggesting absence of heterogeneity. Therefore, we used the fixed-effect model to synthesize the data. The pooled OR for AA genotype versus the widetype GG and heterozygous GA genotype was $0.46(95 \% \mathrm{CI}=0.30-0.70)$, and the $Z$-test for overall effect was $3.63(\mathrm{P}=0.0003)$. These results suggested that the AA carriers had a $54 \%$ lower response rate compared with the $\mathrm{G}$ allele carriers $(\mathrm{GA}+\mathrm{GG})$.

\section{XRCC1 Arg194Trp (C>T) polymorphism}

Eleven studies reported the association between XRCC1 Arg194Trp polymorphism and response rate of platinum chemotherapy in advanced NSCLC patients (Table 4). Because 


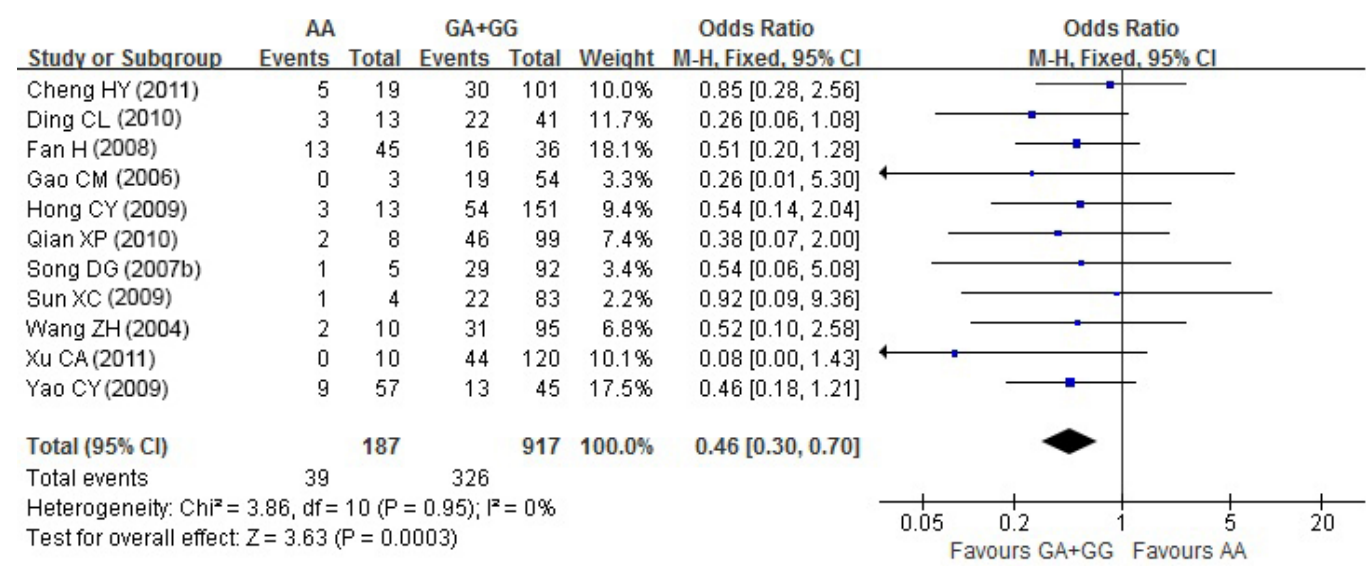

Figure 3. Forest plot of studies on the association between XRCC1 Arg399Gln polymorphism and response rate of platinum chemotherapy in advanced NSCLC patients, using the recessive model (AA vs GA+GG).

\begin{tabular}{|c|c|c|c|c|c|c|c|c|c|}
\hline \multirow[t]{2}{*}{ Published studies } & \multicolumn{3}{|c|}{$\mathrm{T} / \mathrm{T}$} & \multicolumn{3}{|c|}{$\mathrm{C} / \mathrm{T}$} & \multicolumn{3}{|c|}{$\mathrm{C} / \mathrm{C}$} \\
\hline & Response & Non-response & Total & Response & Non-response & Total & Response & Non-response & Total \\
\hline 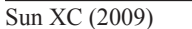 & 5 & 6 & 11 & 18 & 19 & 37 & 8 & 31 & 39 \\
\hline Wang ZH (2004) & 3 & 11 & 14 & 19 & 18 & 37 & 11 & 43 & 54 \\
\hline Hong CY (2009) & 7 & 11 & 18 & 31 & 42 & 73 & 19 & 54 & 73 \\
\hline Song DG (2007b) & 3 & 9 & 11 & 19 & 22 & 41 & 8 & 37 & 45 \\
\hline Jin YW (2006) & 10 & 14 & 24 & 35 & 25 & 60 & 27 & 51 & 78 \\
\hline Gao CM (2006) & 2 & 2 & 4 & 12 & 11 & 23 & 5 & 25 & 30 \\
\hline Yuan P (2006) & 10 & 13 & 23 & 38 & 46 & 84 & 24 & 69 & 93 \\
\hline Ding CL (2010) & 4 & 3 & 7 & 9 & 10 & 19 & 12 & 16 & 28 \\
\hline Qiu LX (2009) & 7 & 6 & 13 & 27 & 23 & 50 & 14 & 30 & 44 \\
\hline Song DG (2007a) & 4 & 12 & 16 & 34 & 32 & 66 & 14 & 70 & 84 \\
\hline Xu CA (2011) & 18 & 18 & 36 & 14 & 26 & 40 & 12 & 42 & 54 \\
\hline
\end{tabular}

Eleven studies reporting response rate by genotypes of TT, CT, and CC separately.

all studies presented data by genotypes of TT, CT, and CC separately, we estimated the association of all 11 studies both in the dominant model and recessive model.

\section{C/C vs $C / T$ T/T for the dominant model}

As shown in Figure 4, P value was 0.77 and $I^{2}$ was $0 \%$ for the heterogeneity of the dominant model for all 11 studies. Overall OR was 0.38 with $95 \% \mathrm{CI}$ of $0.30-0.48$ (P $<$ 0.00001). The results suggested that patients carrying two C alleles (CC) had a $62 \%$ lower response rate compared with those carrying either one or two variant $\mathrm{T}$ alleles $(\mathrm{CT}+\mathrm{TT})$.

\section{$T / T$ vs $C / T C / C$ for the recessive model}

As shown in Figure 5, P value was 0.70 and $I^{2}$ was $0 \%$ for the heterogeneity of the recessive model for all 11 studies. Overall OR was 1.27 with $95 \%$ CI of $0.92-1.77$. The re- 
sults showed that TT carriers had a better response rate compared with the $\mathrm{C}$ allele carriers $(\mathrm{CC}+\mathrm{CT})$. However, the $Z$-test for overall effect was 1.44 and $\mathrm{P}$ was 0.15 , suggesting the difference was not significant.

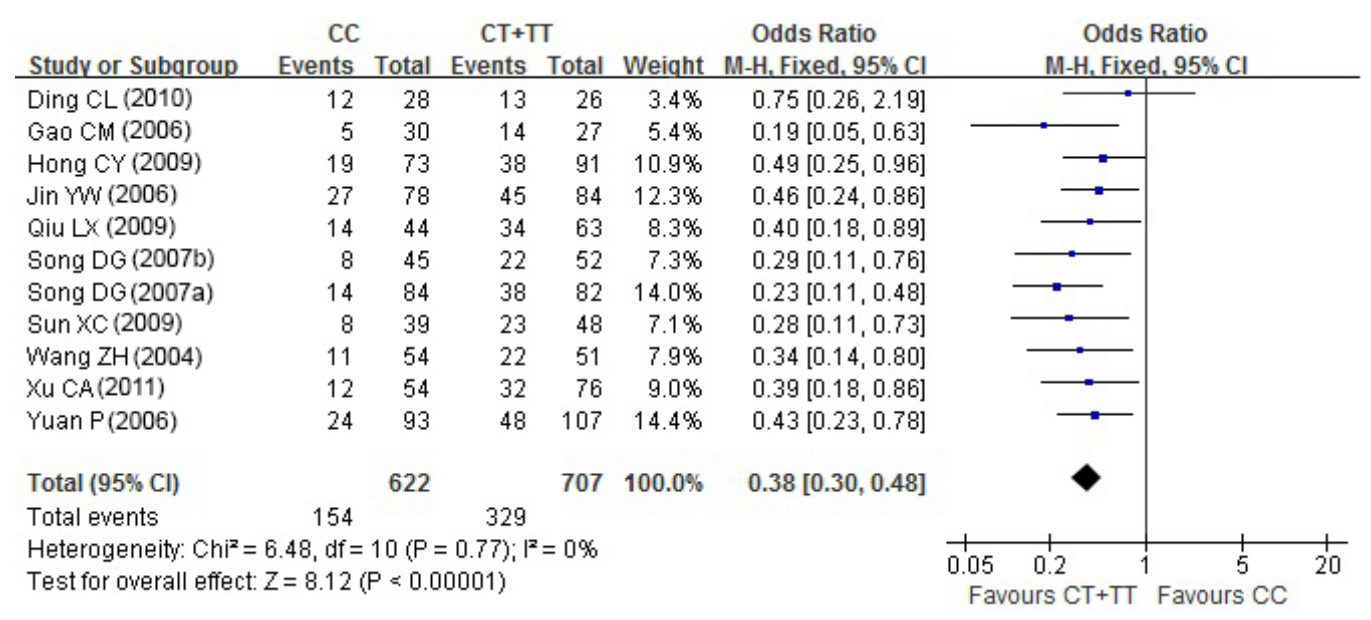

Figure 4. Forest plot of studies on the association between XRCC1 Arg194Trp polymorphism and response rate of platinum chemotherapy in advanced NSCLC patients, using the dominant model (CC vs CT+TT).

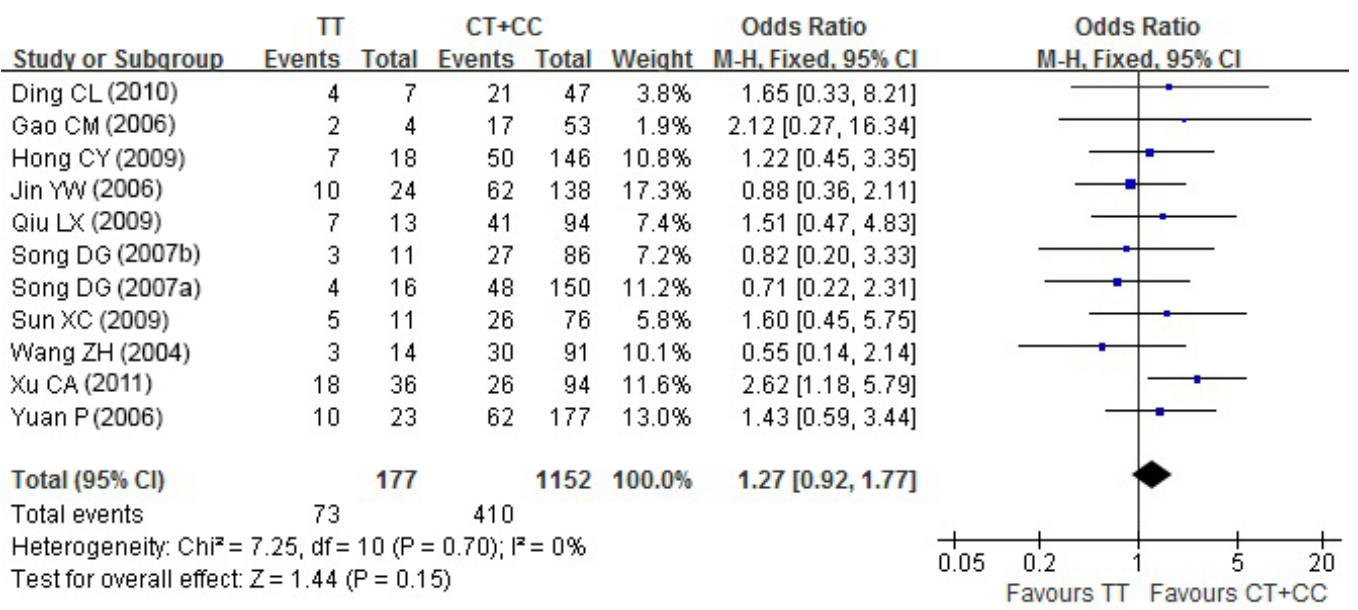

Figure 5. Forest plot of studies on the association between XRCC1 Arg194Trp polymorphism and response rate of platinum chemotherapy in advanced NSCLC patients, using the recessive model (TT vs CT+CC).

\section{Subgroup analyses}

Because the majority of the studies were from Asia and only one from Europe (Table 1), subgroup analyses by ethnicity were not performed. Because most of the included studies used mixed platinum drugs rather than one specific platinum drug (Table 1), subgroup analysis by the type of platinum was not performed. 


\section{Publication bias}

The funnel plots were symmetrical, and neither the Egger test nor Begg test indicated any significant publication bias (all $\mathrm{P}>0.05$ ) for two polymorphisms in both dominant and recessive models. The results suggested a lack of publication bias in the current meta-analysis (Figures 6-9).

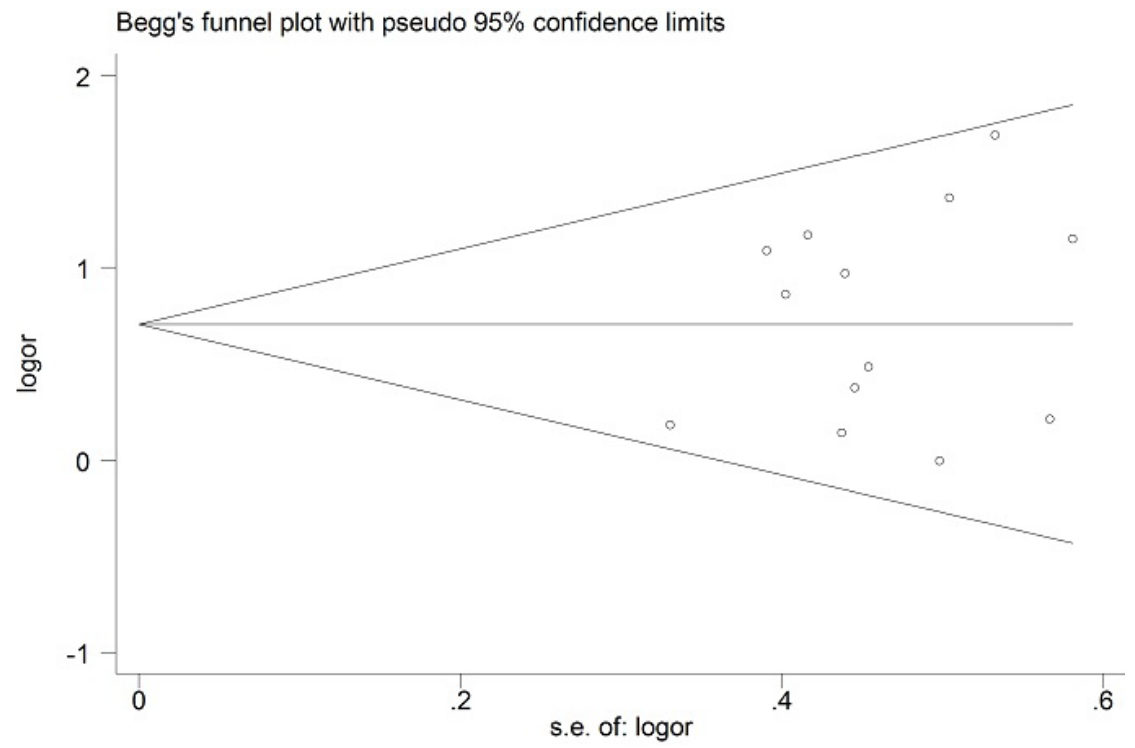

Figure 6. Begg's funnel plot for publication bias in selection of studies on the XRCC1 Arg399Gln polymorphism, using the dominant model.

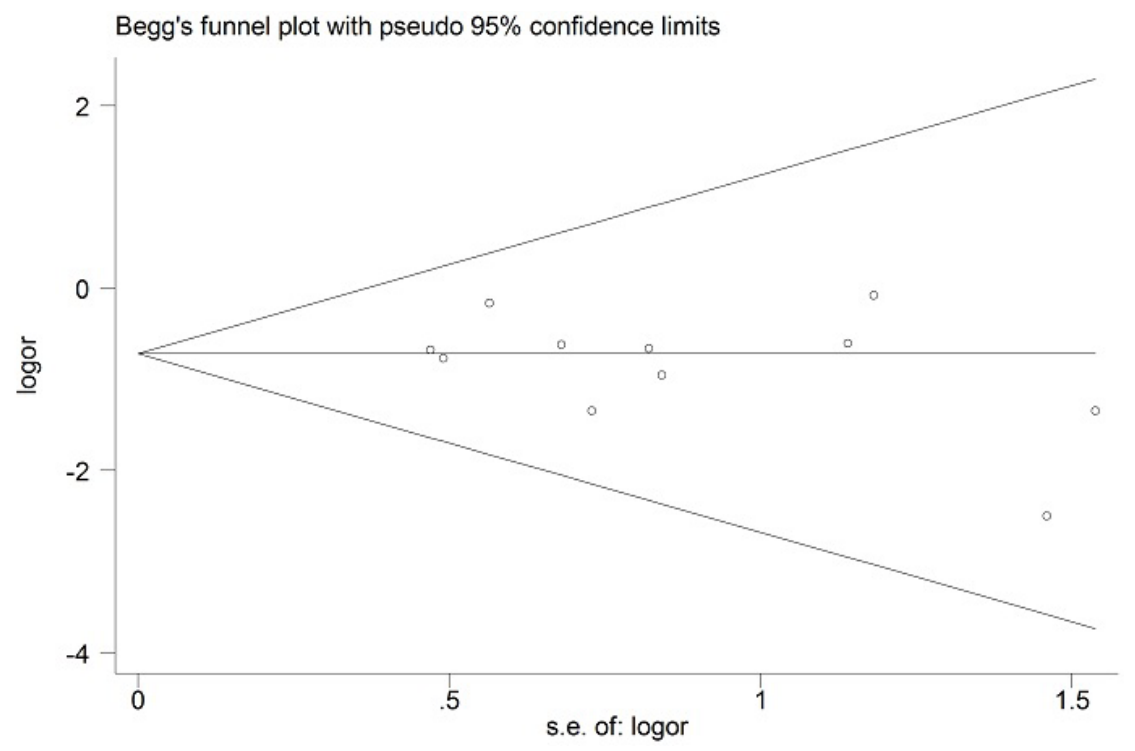

Figure 7. Begg's funnel plot for publication bias in selection of studies on the XRCC1 Arg399Gln polymorphism, using the recessive model. 


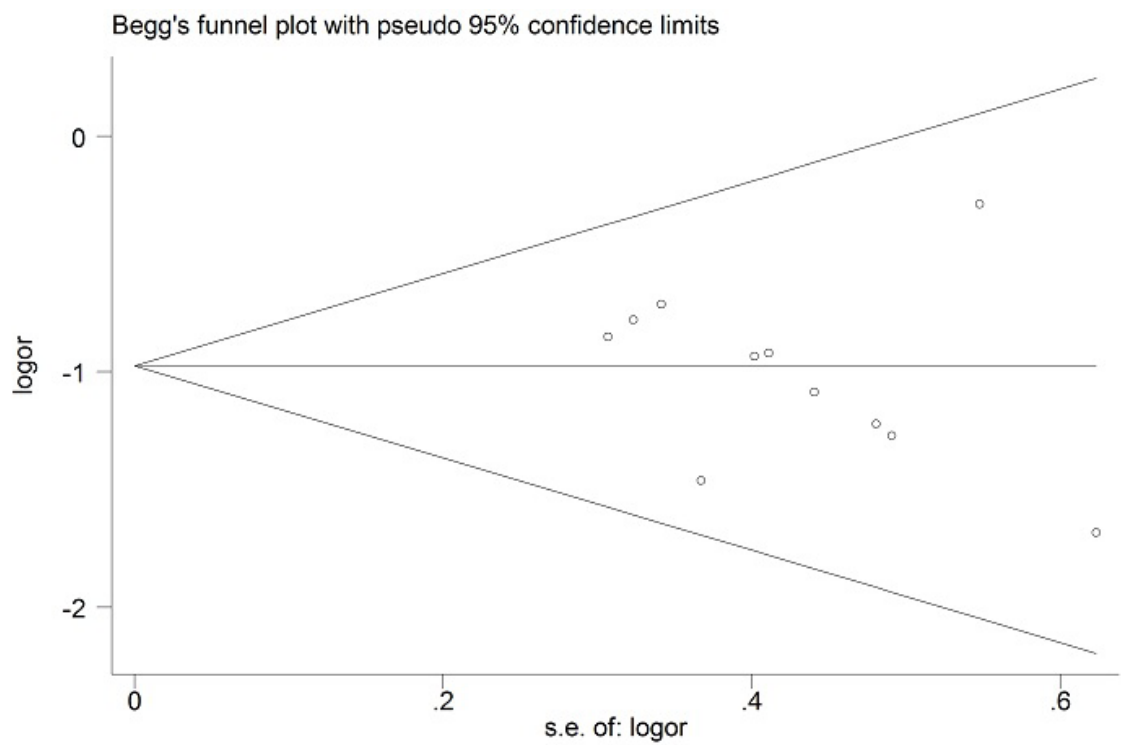

Figure 8. Begg's funnel plot for publication bias in selection of studies on the XRCC1 Arg194Trp polymorphism, using the dominant model.

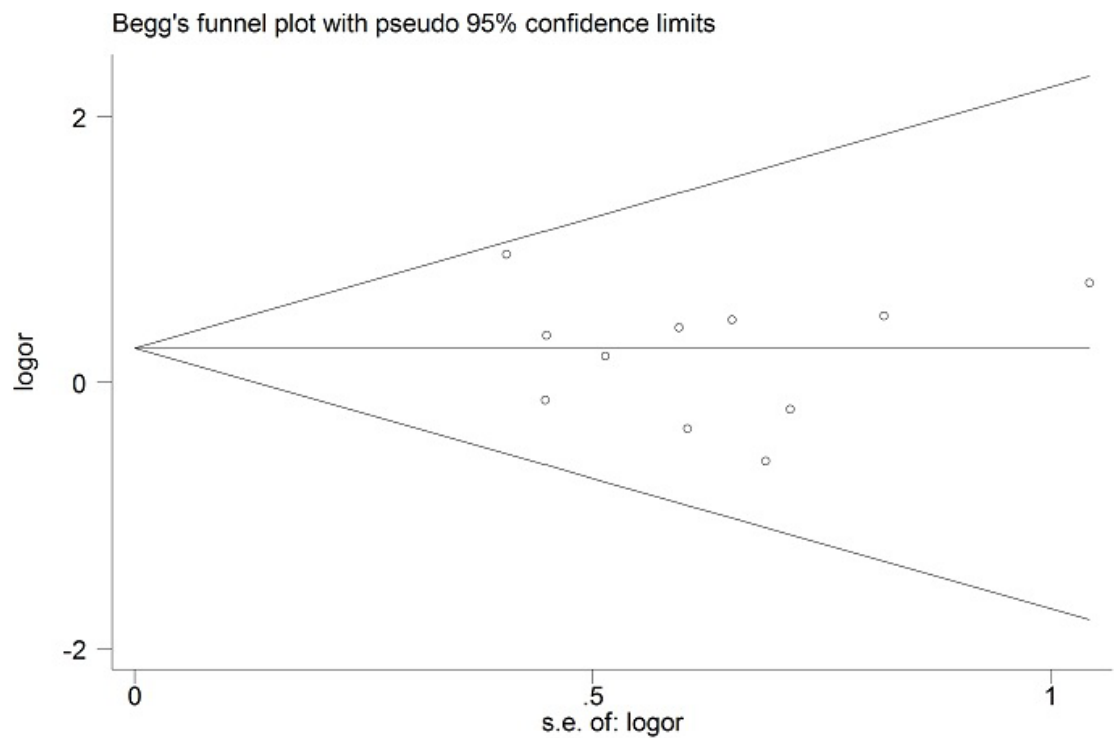

Figure 9. Begg's funnel plot for publication bias in selection of studies on the XRCC1 Arg194Trp polymorphism, using the recessive model.

\section{DISCUSSION}

With a pooled dataset of 2152 advanced NSCLC patients, we found that patients carrying two G alleles (GG) in the XRCC1 Arg399Gln polymorphism exhibited a higher probability 
of response to platinum chemotherapy than those carrying the A allele (GA+AA). Similarly, the AA carriers were less likely to experience response compared with the $\mathrm{G}$ allele carriers $(\mathrm{GA}+\mathrm{GG})$. As for the XRCC1 Arg194Trp polymorphism, patients carrying two $\mathrm{C}$ alleles (CC) had a significantly lower response rate compared with those carrying either one or two variant T alleles (CT+TT). Therefore, we concluded that both XRCC1 Arg399Gln and Arg194Trp polymorphisms were significantly associated with response rate to platinum chemotherapy in advanced NSCLC patients, suggesting that these variants may be predictive factors for treatment response to platinum chemotherapy in NSCLC.

Inconsistent with our results, Horgan et al. reported that NSCLC patients with the GA/ AA genotypes in the XRCC1 Arg399Gln polymorphism exhibited a higher probability of response to platinum-based treatment compared to those with the G/G genotype in their a descriptive review (Horgan et al., 2011). However, after carefully double-checking their reports, we believe that the incorrect use of the Revman software led to the wrong interpretation of the results and conclusion that they drew. A past convention in the Revman software has been that dichotomous outcomes focus on unfavorable outcomes such as mortality, and effect estimates to the left of the vertical line in a forest plot imply a benefit of the experimental intervention, so a default value to the left of the vertical line is "favors treatment" and the right is "favors control". However, it is not universally appropriate. When dichotomous outcomes are favorable outcomes such as effective rate, default value to the left of the vertical line should be changed to "favors control" and the right to "favors treatment". Fortunately, a significant favorable association with the $\mathrm{G}$ alleles in the XRCC1 Arg399Gln polymorphism was also confirmed after interpretation correction.

A recent meta-analysis by Cui et al. (2012) also found a significant association of $X R C C 1$ polymorphisms with platinum response in NSCLC patients, but the results were presented only in the dominant model. Because the biologic effect of the XRCC1 on platinum drug action is inconclusive, the results not presented in both recessive and dominant models could cause some bias in estimates. In addition, quality assessment of the included studies was not performed, although bias can be caused by the quality of the underlying research, such as key components of study design. Therefore, our study sought to improve on several methodological factors. Chiefly, we evaluated associations with the treatment response both in the dominant model (GG vs AA+GA for Arg399Gln and CC vs TT+CT for Arg194Trp) as well as recessive models (AA vs GA+GG for Arg399Gln and TT $v_{s} \mathrm{CT}+\mathrm{CC}$ for Arg194Trp). In addition, we used the Newcastle-Ottawa Scale to perform the quality assessment on all 19 studies, and all studies included in this meta-analysis scored highly.

There were several limitations that should be considered when interpreting the present results. First, the majority of studies had been conducted in Asian populations, and subgroup analyses by ethnicity were not performed because lack of sufficient number of studies, which could limit the generalizability of the findings to other patient populations. However, it is unlikely to change our major conclusions due to the absence of or mild heterogeneity in our pooled analysis, and our results reflected the most current state of this issue in research and clinical practice. Second, stratified analyses by some important clinical parameters, such as smoking history and chemotherapy agents, would be helpful to reduce the heterogeneity and provide additional useful information. However, few of these studies reported these data by subgroups, thus making such analyses impossible.

In conclusion, this meta-analysis suggested that polymorphisms in the XRCC1 gene 
were significantly associated with response rate of platinum chemotherapy in advanced NSCLC patients. XRCC1 polymorphisms may be predictive factors for treatment response to platinum chemotherapy in NSCLC. However, future studies should seek to extend these findings to the complex mechanisms of platinum resistance.

\section{ACKNOWLEDGMENTS}

Research supported by the National Natural Science Foundation of China (\#31171103 and \#81230001) and China Medical Board of New York (\#06-834 to Dr. F.Q. Wen).

\section{Supplementary material}

\section{REFERENCES}

Abdel-Rahman SZ and El-Zein RA (2000). The 399Gln polymorphism in the DNA repair gene XRCC1 modulates the genotoxic response induced in human lymphocytes by the tobacco-specific nitrosamine NNK. Cancer Lett. 159: 63-71.

Audebert M, Salles B and Calsou P (2004). Involvement of poly(ADP-ribose) polymerase-1 and XRCC1/DNA ligase III in an alternative route for DNA double-strand breaks rejoining. J. Biol. Chem. 279: 55117-55126.

Bahl A and Falk S (2001). Meta-analysis of single agents in the chemotherapy of NSCLC: what do we want to know? $B r$. J. Cancer 84: 1143-1145.

Cheng HY, Chen BA, Sun XC, Sun N, et al. (2011). Relationship of single nucleotide polymorphisms and clinical response to platinum-based chemotherapy in advanced non-small cell lung cancer. Jiang Su Med. J. 37: 272-274.

Cui Z, Yin Z, Li X, Wu W, et al. (2012). Association between polymorphisms in XRCC1 gene and clinical outcomes of patients with lung cancer: a meta-analysis. BMC Cancer 12: 71.

Ding CL, Liu LH and Song H (2010). Polymorphism in XRCC1 and sensitivity to platin-based chemotherapy in advanced non-small cell lung cancer. China Pharm. 13: 1399-1401.

Duell EJ, Wiencke JK, Cheng TJ, Varkonyi A, et al. (2000). Polymorphisms in the DNA repair genes XRCC1 and ERCC2 and biomarkers of DNA damage in human blood mononuclear cells. Carcinogenesis 21: 965-971.

Fan H, Huang XW, Zhang Q and Gao LL (2008). Relationship of XRCC1 and XPD gene polymorphisms with chemosensitivity to platinum-based chemotherapy in advanced non-small cell lung cancer. Pract. Geriatr. 22: 306308.

Gao CM, Shi MQ, Wu JZ, Cao HX, et al. (2006). Polymorphisms in XRCC1 gene and sensitivity to gemcitabine/cisplatin chemotherapy in non small cell lung cancer. Practical. J. Cancer 21: 351-353.

Hoeijmakers JH (2001). Genome maintenance mechanisms for preventing cancer. Nature 411: 366-374.

Hong CY, Xu Q, Yue Z, Zhang Y, et al. (2009). Correlation of the sensitivity of NP chemotherapy in non-small lung cancer with DNA repair gene XRCC1 polymorphism. Ai. Zheng. 28: 1291-1297.

Horgan AM, Yang B, Azad AK, Amir E, et al. (2011). Pharmacogenetic and germline prognostic markers of lung cancer. J. Thorac. Oncol. 6: 296-304.

Hu JJ, Smith TR, Miller MS, Mohrenweiser HW, et al. (2001). Amino acid substitution variants of APE1 and XRCC1 genes associated with ionizing radiation sensitivity. Carcinogenesis 22: 917-922.

Jemal A, Bray F, Center MM, Ferlay J, et al. (2011). Global cancer statistics. CA Cancer J. Clin. 61: 69-90.

Jin YW, Liu J and Wang ZH (2006). Prediction of XPD and XRCC1 gene polymorphisms in advanced non-small cell lung cancer patients receiving platinum-based chemotherapy. Shandong Yi Yao 46: 42-43.

Kalikaki A, Kanaki M, Vassalou H, Souglakos J, et al. (2009). DNA repair gene polymorphisms predict favorable clinical outcome in advanced non-small-cell lung cancer. Clin. Lung Cancer 10: 118-123.

Li D, Zhou Q, Liu Y, Yang Y, et al. (2012). DNA repair gene polymorphism associated with sensitivity of lung cancer to therapy. Med. Oncol. 29: 1622-1628.

Lunn RM, Langlois RG, Hsieh LL, Thompson CL, et al. (1999). XRCC1 polymorphisms: effects on aflatoxin B1-DNA adducts and glycophorin A variant frequency. Cancer Res. 59: 2557-2561.

Miller AB, Hoogstraten B, Staquet M and Winkler A (1981). Reporting results of cancer treatment. Cancer 47: 207-214.

Qian XP, Qiu LX, Yang Y, Jiang M, et al. (2010). Predictive value of base-excision repair gene polymorphisms in 
advanced non-small cell lung cancer patients receiving platinum-based chemotherapy. Mod. Oncol. 18: 1303-1304.

Qiu LX, Qian XP, Liu BR, Hu WJ, et al. (2009). Predictive value of XRCC1 polymorphisms in advanced non-small cell lung cancer patients receiving platinum-based chemotherapy. Mod. Oncol. 17: 263-265.

Shellard SA, Fichtinger-Schepman AM, Lazo JS and Hill BT (1993). Evidence of differential cisplatin-DNA adduct formation, removal and tolerance of DNA damage in three human lung carcinoma cell lines. Anticancer Drugs 4: 491-500.

Song DG, Liu J, Wang ZH and Song B (2007a). Predictive value of XRCC1 and XPD on platinum-based chemotherapy in advanced non-small cell lung cancer patients. Chin. J. Gerontol. 27: 1684-1686.

Song DG, Liu J, Wang ZH, Song B, et al. (2007b). Single nucleotide polymorphisms in XRCC1 and clinical response to platin-based chemotherapy in advanced non-small cell lung cancer. Zhong Liu Fang Zhi Yan Jiu 34: 845-847.

Sun XC, Li F, Sun N, Qin SK, et al. (2009). Polymorphisms in XRCC1 and XPG and response to platinum-based chemotherapy in advanced non-small cell lung cancer patients. Lung. Cancer. 65:230-236.

The Cochrane Collaborative Review Group on HIV Infection and AIDS (2009). Editorial Policy: Inclusion and Appraisal of Experimental and Non-Experimental (Observational) Studies. Available at [http://www.igh.org/Cochrane]. Accessed January 8, 2012.

Therasse P, Arbuck SG, Eisenhauer EA, Wanders J, et al. (2000). New guidelines to evaluate the response to treatment in solid tumors. European Organization for Research and Treatment of Cancer, National Cancer Institute of the United States, National Cancer Institute of Canada. J. Natl. Cancer Inst. 92: 205-216.

Wang ZH, Miao XP, Tan W, Zhang XR, et al. (2004). Single nucleotide polymorphisms in XRCC1 and clinical response to platin-based chemotherapy in advanced non-small cell lung cancer. Ai. Zheng. 23: 865-868.

Weaver DA, Crawford EL, Warner KA, Elkhairi F, et al. (2005). ABCC5, ERCC2, XPA and XRCC1 transcript abundance levels correlate with cisplatin chemoresistance in non-small cell lung cancer cell lines. Mol. Cancer 4: 18.

Wells GA, Shea B, O'Connell D and Peterson J (2003). The Newcastle-Ottawa Scale (NOS) for Assessing the Quality of Nonrandomised Studies in Meta-Analyses. Available at [http://www.ohri.ca/programs/clinical epidemiology/oxford. htm]. Accessed January 8, 2012.

Whitehouse CJ, Taylor RM, Thistlethwaite A, Zhang H, et al. (2001). XRCC1 stimulates human polynucleotide kinase activity at damaged DNA termini and accelerates DNA single-strand break repair. Cell 104: 107-117.

Wood RD, Mitchell M, Sgouros J and Lindahl T (2001). Human DNA repair genes. Science 291: 1284-1289.

Xu C, Wang X, Zhang Y and Li L (2011). Effect of the XRCC1 and XRCC3 genetic polymorphisms on the efficacy of platinum-based chemotherapy in patients with advanced non-small cell lung cancer. Zhongguo Fei. Ai. Za Zhi 14: 912-917.

Yao CY, Huang XE, Li C, Shen HB, et al. (2009). Lack of influence of XRCC1 and XPD gene polymorphisms on outcome of platinum-based chemotherapy for advanced non small cell lung cancers. Asian Pac. J. Cancer Prev. 10: 859-864.

Yuan P, Miao XP, Zhang XM, Wang ZH, et al. (2006). XRCC1 and XPD genetic polymorphisms predict clinical responses to platinum-based chemotherapy in advanced non-small cell lung cancer. Zhonghua Zhong Liu Za Zhi 28: 196-199.

Zhou F, Lv HY, Liang J, Yu Z, et al. (2011a). Association of GSTPl and XRCCl genetic polymorphisms with the effects of platinum-based chemotherapy on advanced non-small cell lung cancer patients. Chin. Clin. Oncol. 16: 304-309.

Zhou F, Yu Z, Jiang T, Lv H, et al. (2011b). Genetic polymorphisms of GSTP1 and XRCC1: prediction of clinical outcome of platinum-based chemotherapy in advanced non-small cell lung cancer (NSCLC) patients. Swiss. Med. Wkly. 141: w13275. 